\title{
Study of the effects of natural toothbrush (Salvadora persica) in prevention of dental caries and plaque index
}

\author{
Fatemeh Ezoddini-Ardakani ${ }^{1^{*}}$, Mahmoud Nouri Shadkam ${ }^{2}$, Hasan Fotouhi ${ }^{3}$, \\ Farah Bolouri Kashani ${ }^{3}$, Mahin Abbassi ${ }^{3}$, Zahra Hashemian ${ }^{3}$, Hossein Dehghani ${ }^{3}$, \\ Mohammad Ali Jaffari ${ }^{3}$, Hossein Barzegar ${ }^{3}$, Faezeh Nazarinejhad ${ }^{3}$, Mohammad Kazem Jafari ${ }^{3}$, \\ Abas Heydaripour ${ }^{3}$, Mohammad Javad Dashti ${ }^{3}$, Atefesadat Hedayati ${ }^{3}$, Masoud Masoumi ${ }^{3}$, \\ Somaye Ebrahimi ${ }^{3}$
}

${ }^{1}$ Faculty of Dentistry, Shahid Sadoughi University of Medical Sciences, Yazd, Iran; *Corresponding Author: ezoddini@gamil.com

${ }^{2}$ Faculty of Medicine, Shahid Sadoughi University of Medical Sciences, Yazd, Iran

${ }^{3}$ Shahid Sadoughi University of Medical Sciences, Yazd, Iran

Received 14 June 2012; revised 10 July 2012; accepted 21 July 2012

\section{ABSTRACT}

Background: Nowadays, though more attention is being paid to oral and dental hygiene all over the world, dental caries and periodontal diseases are increasing daily. We decided to study the effectiveness of natural toothbrush in prevention of dental caries and plaque formation. Methods: This analytic, semi-experimental clinical trial included 390 individuals. Subjects were divided into 3 groups: using natural toothbrush, using artificial toothbrush and using both natural and artificial toothbrush. The plaque index and DMFT was assessed at the beginning of the study until 1 year. ANOVA, Kruskal Wallis, LSD, Paired t-test, chi square, Fisher exact and Mc-Nemar tests were used for data analysis. Results: The plaque index in all three groups showed a mean reduction of 0.71 . The mean DMFT in the samples before intervention was $8.38 \pm 4.14$ and increased to $9.1 \pm 4.56$. At the end of the study, the lowest plaque index was observed in the group using both the natural and artificial methods. During one year follow-up, the plaque index decreased 1.16, 0.83, and 0.21 degrees in the first, second and third groups. Conclusion: The increase in DMFT in the group that used artificial toothbrush was more than other groups. Thus, use of natural toothbrush leads to a decrease in growth rate of DMFT. Therefore natural toothbrush can be used for the cleaning of teeth and prevention of dental caries.

Keywords: Salvadora persica; Natural Toothbrush;
Toothbrush and Tooth Paste; Caries; Plaque Index

\section{INTRODUCTION}

Salvadora persica (SP) is a wild plant that grows in the region extending from north western India to Africa. This plant is also known as natural Arak tree, chewing stick, toothbrush and Meswak [1]. Some other applications have been reported for this plant. SP is used for controlling blood sugar level, splenic disorders, deep wounds, and gingival and gastric problems. The extract of the plant boiled in oil is an appropriate ointment for treatment of crush injuries. Its leaves, branches and roots contain a kind of oil with diuretic effects. Its bark is used against stings of poisonous animals and its branches are used for treatment of cough, asthma, scurvy, rheumatism, leprosy, gonorrhea, headache, hepatic problems and various other disorders. Its boiled extract has shown protective effects against ethanol intoxication and stressrelated peptic ulcer in rats and regulating effects on blood sugar levels as well. This plant contains such chemicals as trimethyl amine, organic sulfur compounds and B-sitosterol and small amounts of saponin and lignane glycosides.

Dental plaques are the leading cause of oral diseases and dental caries; so elimination or reduction of plaques is necessary for prevention of these diseases. This plant has been used in Saudi Arabia as a toothbrush since 1400 years ago [1]. It has anti-microbial, anti-inflammatory and hypoglycemic properties. Toothpastes containing the extract of this plant protect gums and teeth. The plant is also used for various other purposes [2]. Chewing sticks are traditionally used for cleaning the teeth $[3,4]$. Although new artificial toothbrushes are considerably used 
in Asian and African countries, chewing sticks are still used for cleaning the teeth $[3,5]$. The benefits of these sticks are due to their constituents and mechanism of action [6]. Recently WHO has proposed the use of these sticks as an effective tool for oral hygiene and their effect against certain aerobic and anaerobic bacteria has been studied [7].

Primary analysis of SP showed that it contains trimethyl amines, salvadorin, chloride, fluoride, silica, sulfur, mustard oil, vitamin C, resin and small amounts of tannin and saponine. These ingredients have antibacterial and anti-febrile properties and protect gums against irritation. Fluoride has anti-caries properties; Silica is abrasive and removes plaques and stains, and mustard oil and sulfur show anti-bacterial effects. In addition, the resin creates a protective layer on the surface of the enamel and tannin has a contractive effect on the mucous membranes thus inhibits the transfer of glycosyl. Some chewing sticks contain such alkaline compounds as anthraquinones (Acacia Arabica), fagaronine and benzophenathridine with anti-bacterial properties [8,9].

Recent in vitro studies on the microbiological effects of Miswak on oral bacteria have shown that its raw extract has a bacteriostatic effect on Bacteriodes Gingivalis. Other studies regarding its chemical compounds and pharmaceutical effects have proved that the high fluoride content in Miswak is responsible for its strong anti-caries effect $[10,11]$.

Many researchers have paid attention to the mechanical cleaning effect of Miswak stick and the anti-microbial activity of its extract. The mechanical cleaning effects of the chewing sticks have been reported as the mechanism of the reduction of plaques and gum inflammation [12].

Nowadays, although more attention is paid to oral and dental hygiene all over the world, the frequency of dental caries and periodontal diseases is increasing which is probably due to increased consumption of carbohydrates, and deficiency of fluoride and calcium in diet and improper oral hygiene [12,13].

Natural toothbrush that was initially proposed by the Holly Prophet, Hazrat Mohammad (SAW), for cleaning and strengthening of teeth and prevention of dental caries more than 1400 years ago is now used in many countries and the significant effects of brushing for prevention of dental caries and oral diseases have been determined. The anti-bacterial, and anti-fungal effects of this natural product and its effect against caries, and plaque formation have been studied and it is proposed that these effects are due to both mechanical and chemical effects $[12,14]$.

Studies have shown that $90 \%$ of rural population of Nigeria and Tanzania (10\% of urban children), 50\% of Saudi Arabians and Indians (65\% rural and 43\% urban population) use Miswak [15-17].

These sticks are effective, inexpensive, abundant, and available and have both mechanical and chemical effects. In the study by Khalid Almas, two types of Miswak sticks were studied and their anti-bacterial effect on streptococcus mutans and fecalis was significant [18].

In the present study, the effects of Miswak on oral and dental hygiene, DMF (decayed, missed, filled), and prevention of caries and dental plaque was studied and compared with common toothpastes and toothbrushes.

\section{METHODS}

This was a semi-experimental clinical trial which was conducted by parallel plan. In a 1 year period (from March 2010 till March 2011) subjects referred to dentistry clinics of health centers in Shahid Sadoughi University of Medical Sciences, Yazd, Iran with following criteria entered the study: Age between 18 and 50 years, living in Yazd, and having at least 20 permanent teeth. Smokers, orthodontic patients, and those with dental anomalies or acute periodontal disease were excluded from the study.

A total of 12 health centers were randomly selected and divided into 3 groups (4 clinics in each group). The groups were randomly assigned to one of the methods of tooth brushing. The methods included: group 1: natural toothbrush (Salvadora persica), group 2: artificial toothbrush and toothpaste, and group 3: both artificial and natural toothbrush.

One hundred and thirty cases in each group were included in the study. Then a questionnaire including name, home address and telephone number for follow up, demographic features, and state of teeth before intervention was filled for each participant. All subjects were similarly trained for oral and dental health and care. Miswak toothbrush (Figure 1) was given to the natural toothbrush group and they were trained for its use. The second group received artificial toothbrush and toothpaste and was trained for its use, while the third group received both natural and artificial toothbrush and toothpaste. All participants were asked to brush their teeth 3 times a day and to refer every three months until 1 year and the state of their oral and dental care was recorded. The subjects in the third group were asked to brush their teeth two times with one method and one time with another and change this arrangement every other day. They were provided by new toothpaste and toothbrushes as necessary in each visit. At the end of one year, the plaque index and number of decayed, filled and extracted teeth (due to caries) was evaluated.

The manager of the dentistry clinic and a dentist in each center attended a 2-day workshop about the method of teaching tooth brushing with SP at the deputy of health 


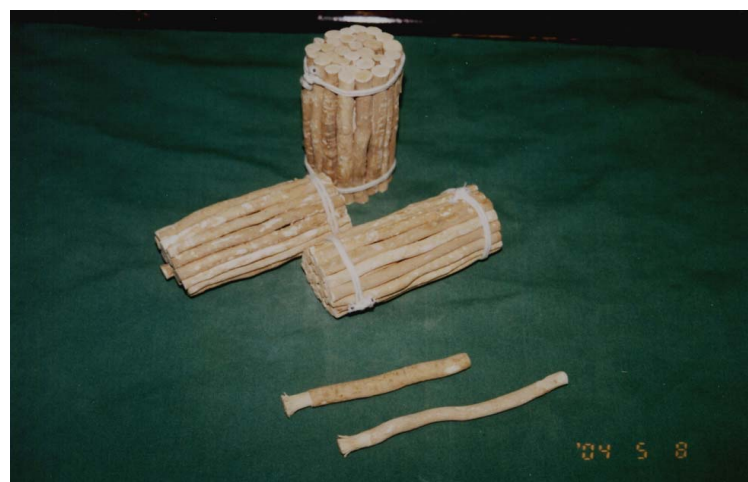

Figure 1. Natural toothbrush.

of the university. They were also trained how to determine the plaque index and state of tooth caries. On the basis of standard references of reconstructive dentistry, tooth caries was classified into 6 caries levels (CL):

CL I: Occlusal surface of the posterior teeth, palatal surface of the anterior teeth, and buccal and lingual surfaces of the upper contour of the teeth.

CL II: Mesial and distal surfaces of the posterior teeth.

CL III: Mesial and distal surfaces of the anterior teeth, incisal border not involved.

CL IV: Mesial and distal surfaces of the anterior teeth with involvement of the incisal border CL V: Buccal and lingual surfaces in the one third of gingival area.

CL VI: Tip of cusp.

Plaque index was graded 0 - 3 as follows:

0 : Plaque not visible and not observed even on rubbing the probe.

1: Plaque not visible but observed after rubbing the probe or using the tablet.

2: Plaque visible and observed after rubbing the probe against the gum margins as well.

3: Plaque visible and covering the dental margins and even extending to the teeth surface.

The data was analyzed by SPSS (ver. 17) using ANOVA, Kruskall Wallis, paired-t-test, chi square, Fisher exact and Mc-Nemar tests. LSD method was used for double comparisons.
No expenses were incurred upon the cases and they were explained in detail about the study at the beginning. After explaining the research protocol, an informed consent was obtained from each subject. The proposal of this study was approved by the ethics committee of Shahid Sadoughi University of Medical Sciences.

\section{RESULTS}

A total of 390 subjects were divided into 3 groups: natural toothbrush (Salvadora persica), artificial toothbrush and toothpaste and both methods. Ultimately, 35 subjects failed to continue to the end and 355 cases were evaluated.

The mean age of the population under study was 28.98 \pm 6.08 years (range: 18 - 50 years). The mean age was not significantly different among 3 groups (ANOVA test, $\mathrm{P}$ value $=0.435)$. Ninety eight $(27.6 \%)$ and $253(72.4 \%)$ subjects were males and females, respectively. This ratio was not significantly different among three groups (Chi square test, $\mathrm{P}$ value $=0.083$ ). On follow-up evaluations, the mean number of tooth brushings increased from 1.11 to 1.54 times per day and the use of dental floss increased from $26.8 \%$ at the beginning of the study to $36.6 \%$ at the end of the study. The mean decrease in the plaque index was 0.71 degrees in all subjects.

Table 1 compares the educational state of subjects in 3 groups. Educational state was not significantly different among 3 groups ( $\mathrm{P}$ value $=0.256$ ).

Table 2 shows the trend of the mean number of tooth brushings per day in follow-up evaluations. The difference became significant after a period of 3 months with a $P$ value of 0.004 . LSD test showed that the mean number of tooth brushings in the first group was significantly lower than the other groups after 3 months $(\mathrm{P}$ value $=$ 0.046 and 0.001 in comparison with second and third groups, respectively); although the comparison between second and third groups failed to show a significant difference $(\mathrm{P}$ value $=0.137)$. The difference between first group and the other groups was significant at 6,9 , and 12 months follow-up evaluations as well ( $\mathrm{P}$ value $=0.019$

Table 1. Comparison of educational state among 3 groups.

\begin{tabular}{|c|c|c|c|c|c|c|c|c|}
\hline \multirow{3}{*}{ Educational state } & \multicolumn{6}{|c|}{ Group } & \multirow{2}{*}{\multicolumn{2}{|c|}{ Total }} \\
\hline & \multicolumn{2}{|c|}{ Natural toothbrush } & \multicolumn{2}{|c|}{ Artificial toothbrush } & \multicolumn{2}{|c|}{ Both methods } & & \\
\hline & Number & Percent & Number & Percent & Number & Percent & Number & Percent \\
\hline Primary school & 11 & 10.9 & 22 & 16.5 & 12 & 9.9 & 45 & 12.7 \\
\hline Guidance school & 16 & 15.8 & 32 & 24.1 & 23 & 19 & 71 & 20 \\
\hline High school & 31 & 30.7 & 40 & 30.1 & 39 & 32.2 & 110 & 31 \\
\hline University & 43 & 42.6 & 39 & 29.3 & 47 & 38.8 & 129 & 36.3 \\
\hline Total & 101 & 100 & 133 & 100 & 121 & 100 & 355 & 100 \\
\hline
\end{tabular}


Table 2. The mean $( \pm S D)$ frequency of tooth brushings per day in the three groups during follow-up.

\begin{tabular}{|c|c|c|c|c|c|}
\hline \multirow{2}{*}{ Follow-up period } & \multicolumn{3}{|c|}{ Group } & \multirow{2}{*}{$\begin{array}{c}\text { Total } \\
(\mathrm{N}=355)\end{array}$} & \multirow{2}{*}{ P value } \\
\hline & $\begin{array}{l}\text { Natural toothbrush } \\
\quad(\mathrm{N}=101)\end{array}$ & $\begin{array}{l}\text { Artificial toothbrush } \\
\qquad(\mathrm{N}=133)\end{array}$ & $\begin{array}{l}\text { Both methods } \\
\quad(\mathrm{N}=121)\end{array}$ & & \\
\hline Before intervention & $1.17(0.75)$ & $1.02(0.61)$ & $1.15(0.62)$ & $1.11(0.66)$ & 0.155 \\
\hline After 3 months & $1.12(0.69)$ & $1.29(0.60)$ & $1.41(0.65)$ & $1.28(0.65)$ & 0.004 \\
\hline After 6 months & $1.24(0.71)$ & $1.45(0.68)$ & $1.69(0.66)$ & $1.47(0.7)$ & 0.000 \\
\hline After 9 months & $1.32(0.67)$ & $1.43(0.65)$ & $1.68(0.66)$ & $1.48(0.67)$ & 0.000 \\
\hline After 1 year & $1.48(0.72)$ & $1.43(0.65)$ & $1.7(0.66)$ & $1.54(0.68)$ & 0.003 \\
\hline
\end{tabular}

and 0.0001 after 6 months for 2nd and 3rd groups, respectively). Figure 2 compares the use of dental floss before and after intervention. Mc-Nemar test showed a significant difference among groups ( $\mathrm{P}$ value $<0.001$ ).

Plaque index directly determines the effectiveness of tooth brushing. At the beginning of the study, only $12.1 \%$ of subjects were free from plaques on their teeth surfaces (similar in 3 groups). After one year, the lowest plaque index was observed in the group using both the natural and artificial methods. Table 3 compares the plaque index among 3 groups. During one year follow-up, the plaque index decreased 1.16, 0.83 , and 0.21 degrees in the first, second and third groups, respectively. Kruskall Wallis test showed a significant difference among 3 groups ( $\mathrm{P}$ value $<0.001$ ).

Table 4 compares DMF variables at the beginning and end of the study. LSD test showed a significant difference between the 1st and 2nd group (P value $<0.001)$ and between 2nd and 3rd group ( $\mathrm{P}$ value $<0.001$ ), but it failed to show a significant difference between 1st and 3rd group ( $\mathrm{P}$ value $=0.565$ ). The changes in DMF in the three groups after one year is depicted in Table 5.

It was observed that the increase in DMF in the natural toothbrush group was 1.18 fold of the control group using artificial toothbrush and toothpaste and this increase in the group using both methods was half of the natural toothbrush group. This relationship was analyzed by ANOVA test and the observed difference was significant (P value $<0.001)$.

\section{DISCUSSION}

In the present study, a total of 355 cases were followed every 3 months for a period of one year. The plaque index and the number of decayed, filled and extracted (due to caries) teeth were evaluated.

The efficacy of chewing sticks in oral hygiene has been evaluated by various studies [17,19-21]. Al-Lafi and $\mathrm{Kh}$. Almas et al. showed that streptococcus fecalis is the most susceptible microorganism to Salvadora persica $[7,22]$. In the present study the incidence and progression of dental caries decreased after natural toothbrush use that is probably due to its anti-microbial properties. Kh. Almas reported that streptococci decreased significantly in the group using natural toothbrush compared to the group using artificial toothbrush and toothpaste $(\mathrm{P}=$ 0.013 ), but the difference in lactobacilli ws not significant $(P=0.147)$ [23]. In the present study, dental caries was reduced. Wolinsky and coworkers [24] showed that Salvadora persica reduces the colonization power of certain streptococci on the teeth surface. The state of the teeth health regarding the number of decayed, filled and extracted teeth was similar in all groups at the beginning of the study and there was significant reduction in DMF at the end of the study (P value $=0.0001)$, along with the reduction in caries that could be due to the anti-microbial properties of natural toothbrush [10]. Almas and Mehanna in their studies stated that the antibiotics existing in Salvadora persica could interfere with the bacteria and prevent their aggregation $[18,25]$.

Fluoride is another compound that could affect the glycolytic enzymes of bacteria. Benzilisothiocyanate (BIT) that is naturally present in Salvadora persica, prevents the growth of bacteria and their acid production [26]. In addition to the anti-bacterial effects, chewing sticks remove the plaques physically and this is very effective in prevention of caries. Reduction of caries during one year of the study proves this claim.

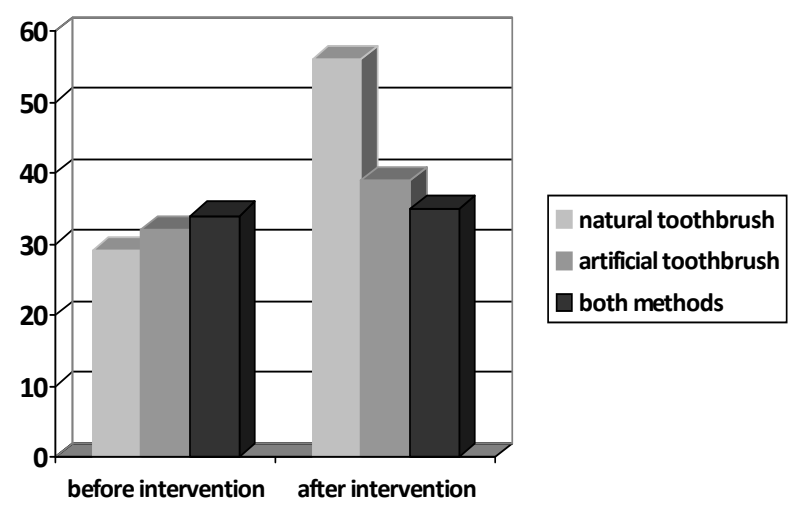

Figure 2. Comparison of the frequency of dental floss use before and after intervention in the groups under study. 
Table 3. Comparison of plaque index at the beginning of the study and after one year intervention in the groups under study.

\begin{tabular}{|c|c|c|c|c|c|c|c|c|c|c|}
\hline \multirow{3}{*}{ Time period } & \multirow{3}{*}{ Plaque index } & \multicolumn{6}{|c|}{ Group } & \multirow{2}{*}{\multicolumn{2}{|c|}{ Total }} & \multirow{3}{*}{$P$ value } \\
\hline & & \multicolumn{2}{|c|}{ Natural toothbrush } & \multicolumn{2}{|c|}{ Artificial toothpaste } & \multicolumn{2}{|c|}{ Both methods } & & & \\
\hline & & Number & Percent & Number & Percent & Number & Percent & Number & Percent & \\
\hline \multirow{4}{*}{ Beginning of the study } & 0 & 10 & 9.9 & 14 & 10.5 & 19 & 15.7 & 43 & 12.1 & \multirow{4}{*}{$\begin{array}{c}\text { C } \\
0.608\end{array}$} \\
\hline & 1 & 43 & 42.6 & 67 & 50.4 & 56 & 46.3 & 166 & 46.8 & \\
\hline & 2 & 28 & 27.7 & 33 & 24.8 & 29 & 24.0 & 90 & 25.4 & \\
\hline & 3 & 20 & 19.8 & 19 & 14.3 & 17 & 14.00 & 56 & 15.8 & \\
\hline \multirow{4}{*}{ One year after intervention } & 0 & 43 & 42.6 & 17 & 12.8 & 96 & 79.3 & 156 & 43.9 & \multirow{4}{*}{$\begin{array}{c}\mathrm{F} \\
0.000\end{array}$} \\
\hline & 1 & 41 & 40.6 & 79 & 59.4 & 25 & 20.7 & 145 & 40.8 & \\
\hline & 2 & 17 & 16.8 & 29 & 21.8 & 0 & 0 & 46 & 13.00 & \\
\hline & 3 & 0 & 0 & 8 & 6.00 & 0 & 0 & 8 & 2.3 & \\
\hline
\end{tabular}

C: Chi square test; F: Fisher Exact test.

Table 4. The mean DMF of the three groups before and after the intervention.

\begin{tabular}{|c|c|c|c|c|c|c|c|c|c|}
\hline \multirow{2}{*}{ Group } & \multirow{2}{*}{$\begin{array}{l}\text { Number of } \\
\text { samples }\end{array}$} & \multicolumn{4}{|c|}{ Before study } & \multicolumn{4}{|c|}{ After study } \\
\hline & & Mean DMF & SD & Minimum & Maximum & Mean DMF & $\mathrm{SD}$ & Minimum & Maximum \\
\hline $\begin{array}{l}\text { Artificial toothpaste } \\
\text { and toothbrush }\end{array}$ & 133 & 9.00 & 3.96 & 0 & 17 & 10.81 & 4.64 & 0 & 21 \\
\hline Natural toothbrush & 101 & 7.79 & 3.69 & 1 & 22 & 7.89 & 3.72 & 1 & 22 \\
\hline Both methods & 121 & 8.18 & 4.62 & 0 & 20 & 8.23 & 4.58 & 0 & 20 \\
\hline Total & 355 & 8.38 & 4.14 & 0 & 22 & 9.1 & 4.56 & 0 & 22 \\
\hline$P$ value & & \multicolumn{4}{|c|}{0.071} & \multicolumn{4}{|c|}{$<0.001$} \\
\hline
\end{tabular}

Table 5. Mean increase in DMF over a period of one year in the three groups.

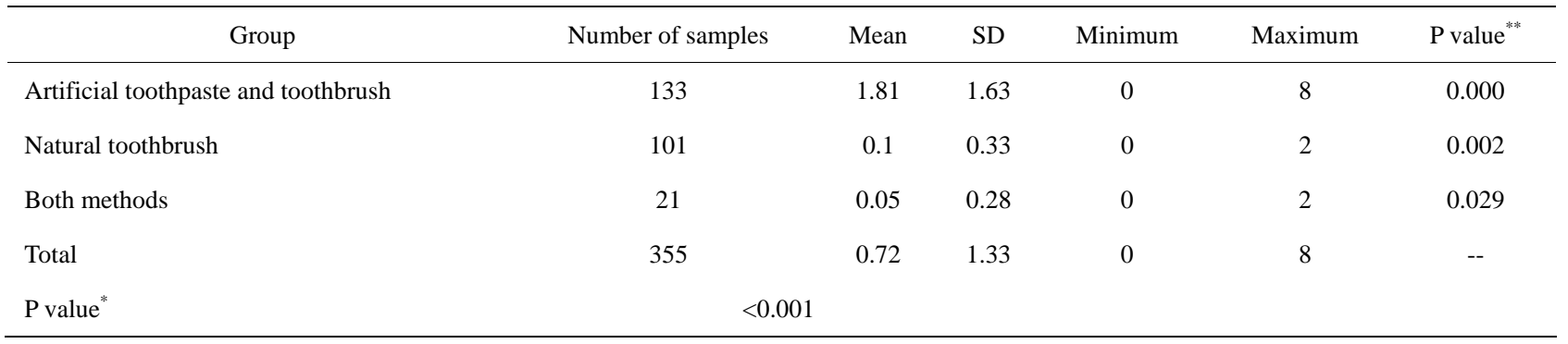

"ANOVA; ${ }^{* *}$ Paired test.

In the study of M.A. Eid et al. [6], the capabilities of artificial and natural toothbrushes in plaque removal and the relationship between Miswak and periodontal health were studied. The results showed that natural toothbrush use results in more accurate and better removal of plaques. Thus Miswak ensures periodontal health by reducing plaque formation. It seems that the combination of chemical and physical properties of Miswak provides this effect. In the present study, the number of decayed and filled teeth was less in the group using natural tooth- brush as well.

Similarly, Mosadomi [27] and Farah [28] reported that Salvadora persica has anti-microbial effects and a substantial amount of fluoride. In the present study it was concluded that sticks of Salvadora persica have substantial anti-microbial effects.

The use of natural toothbrush not only removes plaques better than artificial toothbrush but also it possibly prevents its formation and fights against oral microorganisms. In the present study, the increase in DMF was 
small in the study group that could be due to the antimicrobial properties and fluoride content of natural toothbrush. Darout and coworkers [29] concluded that the dental and periodontal condition of those using natural toothbrush was better than those using artificial toothbrush and toothpaste consistent with the present study.

In the study by Norton in Ghana, it was shown that the rate of plaque formation, and creation and progression of tooth caries was less in natural toothbrush users than those using artificial toothbrush and tooth paste which was in agreement with our study [30].

In the study in Ethiopia, Nigeria and Saudi Arabia wherein natural and artificial toothbrushes were compared, it was shown that natural toothbrush is more effective than artificial toothbrush in removal of dental plaque [31-33].

The total fluoride content of Miswak sticks is approximately $1.02 \mu \mathrm{g} / \mathrm{g}$. Farah [28] realized that SP chewable sticks, Neem-kikar, walnut and Pekujebu contain 2.8, 1.0, 0.5 and $0.2 \mu \mathrm{g} / \mathrm{ml}$ fluoride, respectively. Crystallographic assessment with fluorescence and microanalysis with $\mathrm{X}$ ray showed that Salvadora persica contains more calcium and phosphorous [34]. It was also observed the hot taste and chewing of the stick result in increased flow of saliva and its buffering effect [9]. This could be one of the explanations of decreased caries in the present study.

In the study of Ezoddini et al. on 337 high school students, DMFT was significantly higher in the control group using artificial toothbrush and toothpaste than those using natural toothbrush [35].

Firas et al. studied the effects of the water/alcohol extract of Salvadora persica on oral health. The alcoholic extract was more effective on streptococci, and the strongest effect of the water extract was against streptococcus fecalis. Both extracts had sufficient anti-fungal effects against candida albicans according to the turbidity test [36].

In the present study, there was a slight decrease in the frequency of tooth brushing after three months which is probably due to the more time spent for brushing with natural toothbrush than artificial one.

\section{CONCLUSION}

It can be concluded that Salvadora persica (natural toothbrush) can be used for the cleaning of teeth and prevention of dental caries. Considering the advertisements by the toothpaste manufacturing companies and new products being introduced everyday in the international markets, even if the chewing sticks are not available, toothpastes containing its extract can be used in developing countries.

\section{REFERENCES}

[1] Galati, E.M., Monforte, M.T., Forestieri, A.M., Miceli, N., Bade, A. and Trovato, A. (1999) Salvadora persica L.: Hypolipidemic activity on experimental hypercholesterolemia in rat. Phytomedicine, 6, 181-185. doi:10.1016/S0944-7113(99)80007-5

[2] Ezmirly, S.T. Cheng, J.C. and Wilson, S.R. (2001) Saudi Arabian medicinal plants Salvadora persica. Chemistry and Industry, 21, 191-192.

[3] Kimery, M.J. and Stallard, R.E. (1992) The evolutionary development and contemporary utilization of various oral hygiene procedures. Periodontal Abstract, 16, 90-97.

[4] Sofrata, A.H., Claesson, R.L., Lingström, P.K. and Gustafsson, A.K. (2008) Strong antibacterial effect of miswak against oral microorganisms associated with periodontitis and caries. Journal of Periodontology, 79, 1474-1479. doi:10.1902/jop.2008.070506

[5] Eid, M.A., Selim, H.A. and Al-Shammery, A.R. (1990) The relationship between chewing sticks (Miswak) and periodontal health. Part 1. Review of the literature and profile of the subjects. Quintessence International, 21, 913-917.

[6] Eid, M.A., Al-Shammery, A.R. and Selim, H.A. (1990) The relationship between chewing sticks (Miswak) and periodontal health. Part 2. Relationship to plaque, gingivitis, pocket depth, and attachment loss. Quintessence International, 21, 1019-1022.

[7] Al-Lafi, T. and Ababneh, H. (1995) The effect of the extract of the Miswak (chewing sticks) used in Jordan and the middle East on oral bacteria. International Dental Journal, 45, 218-221.

[8] Amin, T.T. and Al-Abad, B.M. (2008) Oral hygiene practices, dental knowledge, dietary habits and their relation to caries among male primary school children in Al Hassa, Saudi Arabia. International Journal of Dental Hygiene, 6, 361-370. doi:10.1111/j.1601-5037.2008.00310.x

[9] Al-Otaibi, M., Al-Harthy, M., Söder, B., Gustafsson, A. and Angmar-Månsson, B. (2003) Comparative effect of chewing sticks and toothbrushing on plaque removal and gingival health. Oral Health \& Preventive Dentistry, 1, 301-307.

[10] Sofrata, A., Lingström, P., Baljoon, M. and Gustafsson, A. (2007) The effect of miswak extract on plaque $\mathrm{pH}$. An in vivo study. Caries Research, 41, 451-454. doi:10.1159/000107931

[11] Akhtar, M.S. and Agmal, M. (1991) Significance of chewing sticks (Miswak) in oral hygiene from a pharmacological view-point. Journal of Pakistan Medical Association, 31, 89-95.

[12] Akpata, E.S. and Akinrimisi, E.O. (2000) Antibacterial activity of extracts from some African Chewing sticks. Oral Surgery, 44, 717-722.

[13] El-Mostehy, M.R., Al-Jassem, A.A., Al-Yassin, I.A. et al. (1999) Miswak as an oral health device preliminary 
chemical and clinical evaluation. Hamdard, 26, 41-50.

[14] Al-Otaibi, M. (2004) The miswak (chewing stick) and oral health. Studies on oral hygiene practices of urban Saudi Arabians. Swedish Dental Journal Supplement, 167, 2-75.

[15] Mumghamba, E.G., Manji, K.P. and Michael, J. (2006) Oral hygiene practices, periodontal conditions, dentition status and self-reported bad mouth breath among young mothers, Tanzania. International Journal of Dental Hygiene, 4, 166-173. doi:10.1111/j.1601-5037.2006.00186.x

[16] Guile, E.E., Al-Shammery, A.R. and El-Backly, M.N. (1996) Oral health survey of Saudi Arabia: Oral health knowledge attitudes and practice among adults. Journal of Dental Research, 75, 1276.

[17] Akhtar, M. and Ajmal, M. (2000) Significance of chewing sticks (Miswak) in oral hygiene from a pharmacological viewpoint. Journal of the Pakistan Medical Association, 4, 84-95.

[18] Almas, K.H. (1999) The Antimicrobial effects of extracts of azadirachta indica (NEEM) and Salvadora persica (Arak) chewing sticks. Indian Journal of Dental Research, 10, 23-26.

[19] Almas, K., Al-Sanawi, E. and Al-Shahrani, B. (2005) The effect of tongue scraper on mutans streptococci and lactobacilli in patients with caries and periodontal disease. Odontostomatologie Tropicale, 28, 5-10.

[20] Okemwa, K.A., Gatongi, P.M. and Rotich, J.K. (2010) The oral health knowledge and oral hygiene practices among primary school children age 5 - 17 years in a rural area of Uasin Gishu district, Kenya. East African Journal of Public Health, 7, 187-190.

[21] Khoory, T. (1999) The use of chewing sticks in preventive oral hygiene. Clinic Preventive Dentistry, 5, 11-14.

[22] Almas, K., Al-Bagieh, N. and Akpata, E.S. (1997) In vitro antimicrobial effects of freshly cut and 1-month old miswak (chewing stick). Biomedical Letters, 56, 145-149.

[23] Almas, K.H. and Al-Zeid, Z. (2004) The immediate antimicrobial effect of a toothbrush and Miswak on cariogenic bacteria: A clinical study. Journal of Contemporary Dental Practice, 5, 105-114.

[24] Wolinsky, L.E., Mania, S., Nachnani, S. and Ling, S. (1996) The inhibiting effect of aqueous azadirechta indica (neem) extract upon bacterial properties influencing in vitro plague formation. Journal of Dental Research, 75, 816-822. doi:10.1177/00220345960750021301

[25] Mehanna, N. and Reid, G. (2010) Effect of meswak (middle eastern tree bark) on oral pathogens and potential for probiotic applications. Journal of Medicinal Food, 13, 729-732. doi:10.1089/jmf.2009.0051

[26] Al-Bagieh, N. and Weinberg, E. (1999) Benzylisothicyanate: A possible agent for controlling dental caries. $\mathrm{Mi}$ crobios, 39, 143-151.

[27] Mosadomi, H.A. (1987) The effect of crude extracts of nine African chewing sticks on oral anaerobes. Journal of Medical Microbiology, 23, 55-60. doi:10.1099/00222615-23-1-55

[28] Farah, H.H. and Ghandour, I.A. (2009) Periodontal health status of 12-year-old Sudanese schoolchildren and educational level of parents in Khartoum province. Odontostomatologie Tropicale, 32, 25-33.

[29] Darout, I.A., Albandar, J.M. and Skaug, N. (2000) Periodontal status of adult Sudanese habitual users of miswak chewing sticks or toothbrushes. Acta Odontologica Scandinavica, 58, 31-37. doi:10.1080/000163500429398

[30] Norton, M.R. and Addy, M. (1989) Chewing sticks versus toothbrushes in West Africa. A pilot study. Clinical Preventive Dentistry, 11, 11-13.

[31] Al-Sohaibani, S. and Murugan, K. (2012) Anti-biofilm activity of Salvadora persica on cariogenic isolates of Streptococcus mutans: In vitro and molecular docking studies. Biofouling, 28, 29-38. doi:10.1080/08927014.2011.647308

[32] Magbool, G. (1992) Prevalence of dental Caries in school children in Al-Khabar Saudi Arabia. Journal of Dentistry for Children, 59, 384-386.

[33] Char, D.C.N., Dogao, A.V. and Dogan, M.M. (1987) XRF and EMPA evaluation of middle eastern toothbrush Salvadora persica. Journal of Electron Microscopy Technology, 5, 145.

[34] George, S.J., Drury, O.B., Fu, J.X., Friedrich, S., Doonan, C.J., George, G.N., White, J.M., Young, C.G. and Cramer, S.P. (2009) Molybdenum X-ray absorption edges from $200-20,000 \mathrm{eV}$, the benefits of soft X-ray spectroscopy for chemical speciation. Journal of Inorganic Biochemistry, 103, 157-167. doi:10.1016/j.jinorgbio.2008.09.008

[35] Ezoddini-Ardakani, F. (2010) Efficacy of miswak (Salvadora persica) in preventing dental caries. Health, 2, 499-503. doi:10.4236/health.2010.25074

[36] Al-Bayati, F.A. and Sulaiman, K.D. (2008) In vitro antimicrobial pathogens in Iraq. Turkish Journal of Biology, 32, 57-62. 